\title{
Evaluation of Effectiveness and Tolerability of Fondaparinux in the Management of Symptomatic Acute Coronary Syndrome: A Real-World Evidence- Based Study on an Indian Population
}

\author{
Jamshed Dalal · J. C. Mohan · Sunil Sathe · A. Sreenivas Kumar • \\ Jagdish Hiremath · Mohammed Yunus Khan · Kumar Gaurav • \\ Amey Mane $\cdot$ Sucheta Pandit · Bhavesh Meel · Anand Subramaniyan
}

Received: October 4, 2021 / Accepted: January 10, 2022 / Published online: February 9, 2022

(C) The Author(s) 2022

\section{ABSTRACT}

Introduction : Fondaparinux is a low molecular weight heparin anticoagulant used to manage the full spectrum of acute coronary syndrome (ACS) patients and has proved its efficacy and safety in multiple clinical trials. However, there are limited data available showing whether the same results could be reproduced in real-world practice on an Indian population. Our objective

Supplementary Information The online version contains supplementary material available at https:// doi.org/10.1007/s40119-022-00253-X.

\section{J. Dalal}

Kokilaben Dhirubhai Ambani Hospital, Mumbai, India

e-mail: jjdalal@hotmail.com

J. C. Mohan

Fortis Hospital, Shalimar Bagh, Delhi, India

e-mail: a51hauzkhas@gmail.com

S. Sathe

Cardiac Care and Counselling Centre, Pune, India e-mail: svscardcare@gmail.com

\section{A. S. Kumar}

Apollo Hospitals, Jubilee Hills, Hyderabad, India

e-mail: arramraj@yahoo.com

J. Hiremath

Ruby Hall Clinic, Pune, India

e-mail: drjagdishhiremath@gmail.com was to determine the effectiveness and tolerability of fondaparinux in the management of symptomatic ACS in real-world clinical practice. Methods: The EMR data of hospitalized ACS patients $(n=611)$, from January 2015 to January 2020, representing UA or NSTEMI or STEMI and were prescribed fondaparinux ( $2.5 \mathrm{mg}$ once daily) to manage ACS were analyzed. The effectiveness was analyzed as recurrence of ACS and tolerability as total incidence of major bleeding during hospitalization, at 30 days and 180 days. Appropriate statistical analysis was used with a statistically significance of $p$ value $<0.05$.

M. Y. Khan $(\bowtie) \cdot$ K. Gaurav · A. Mane $\cdot$ S. Pandit Dr. Reddy's Laboratories Ltd, Hyderabad, India e-mail: doctorkhan26@gmail.comK. Gaurav e-mail: kumargaurav2@drreddys.com
A. Mane
e-mail: amey.mane@drreddys.com
S. Pandit
e-mail: suchetaakshay.p@drreddys.com
B. Meel
Heart and General Hospital, Jaipur, India e-mail: bhavesh_meel@rediffmail.com
A. Subramaniyan
Kauvery Heartcity, Tiruchirappalli, Tamilnadu, India
e-mail: anandsubbu81@yahoo.co.in


Results: The incidence of recurrent ACS was not seen during hospitalization and in the first 30 days, while in only $0.65 \%(n=4)$ patients, ACS reoccurred within 180 days. In a mean duration of $172.75 \pm 3.20$ days, UA was reported in $0.49 \%(n=3)$ patients, NSTEMI in $0.16 \%$ $(n=1)$ of patients, and STEMI was not documented. None of the major bleeding events occurred during the entire study period, whereas minor bleeding events were reported during hospitalization $0.98 \%(n=6)$ and at 30 days $0.16 \%(n=1)$. The bleeding events were statistically insignificant ( $p$ value $>0.05)$. No incidences of stent thrombosis were reported during the entire study period.

Conclusions: In the real world, fondaparinux was found to be effective and tolerable when used to manage symptomatic ACS patients regardless of revascularization procedure with no incidence of stent thrombosis, and minimal recurrent ACS and insignificant increase in bleeding events.

Keywords: ACS; Fondaparinux; EMR; Realworld evidence; Stent thrombosis

\section{Key Summary Points}

The current RWE study was specifically designed to determine the effectiveness and tolerability of the fondaparinux prophylaxis in symptomatic acute coronary syndrome (ACS).

The effectiveness was analyzed as recurrence of ACS and tolerability as total incidence of major bleeding during hospitalization, at 30 days and 180 days.

The study provided evidence of effectiveness and tolerability of fondaparinux and demonstrated it as a preferable choice in terms of management and prevention of ischemic events and major bleeding after initiation of the treatment in ACS patients in a real-world setting.
The positive effects of fondaparinux are due to its ability to initiate selective inhibition of factor Xa. It is also easy to use (2.5 mg pre-filled injection once daily for all ACS patients) as no dose adjustments are necessary, which limits dosing errors.

\section{INTRODUCTION}

Coronary artery disease (CAD) is a pathological process characterized by atherosclerotic plaque accumulation in the epicardial arteries, whether obstructive or non-obstructive. The dynamic nature of the CAD process results in various clinical presentations, which can be conveniently categorized as either acute coronary syndrome (ACS) or chronic coronary syndrome (CCS).

ACS is commonly associated with clinical manifestations that constitute a continuum of intensity from unstable angina to non-ST-segment elevation MI (NSTEMI), (ST-segment elevation generally absent) to ST-segment elevation MI (STEMI) [ST-segment elevation usually present], according to enzymatic and electrocardiographic changes [1-7]. All of these conditions are triggered by the disruption of an atheromatous plaque that results in partial or complete occlusion of infract-related artery thrombosis, resulting in impairment of coronary blood flow $[3,8,9]$. Plaque disruption contributes to thrombus formation, which results in the activation of platelets and the coagulation cascade, leading to ACS development. The thrombus may be entirely or partially occlusive $[9,10]$.

Regardless of the availability of these treatments, up to $10 \%$ of patients die or suffer from recurrence infraction during hospitalization, and up to $7 \%$ die within 1 month of discharge [11-13]. These outcomes might be unreliable pharmacokinetics and low bioavailability, nonspecific inhibition of different factors, incorrect dose, and frequent monitoring. Thus, a major therapeutic advantage would be a drug with a simple dosing regimen with no need to monitor 
coagulation parameters and more clinically effective by reducing the bleeding complications $[11,14]$.

In the treatment of ACS, one such molecule is 'fondaparinux', the first synthetic pentasaccharide that selectively inhibits activated factor $\mathrm{Xa}$ by binding to a centrally located antithrombin coagulation factor. It is a single chemical entity composed of five saccharides, specifically designed to bind strongly and selectively to antithrombin $[3,6,11,14]$. The prefilled 2.5-mg-once-daily subcutaneous injection of fondaparinux needs no dose adjustment for any age, it is absorbed rapidly and completely, and results in 24-h coverage with no need to monitor coagulation parameters. Furthermore, no clinically relevant interactions have been observed with several other commonly used antithrombotic drugs.

Multiple randomized clinical trials (RCTs) have demonstrated the safety and efficacy of this prefilled anticoagulant in various clinical situations and have unequivocally proved that fondaparinux is better in reducing the incidence of recurrence and bleeding events. However, there are limited data showing whether the same results could be reproduced in the general Indian population in real-world practice with no pre-defined clinical settings like RCTs. Also, the net clinical benefit description of this anticoagulant across the spectrum of patients with ACS has not been comprehensively studied in real-world practice in the Indian population. Therefore, this study was designed to provide the real-world evidence-based insights about the effectiveness and tolerability of fondaparinux in the management of the spectrum of symptomatic ACS in the Indian population.

\section{METHODS}

This retrospective, longitudinal, real-world, observational study data was collected from the cardiology departments of multiple tertiary care centers over a period of 5 years from January 2015 to January 2020. About 620 EMR patients were screened for the selection of the study population. A total of 611 patients met the inclusion and exclusion criteria and were included in the final analysis.

An independent ethics committee (IEC), Royal Pune Independent Ethics Committee, located in Pune, India, approved the study protocol and also gave permission to analyze the available retrospective data. This was a retrospective study and used anonymized or anonymous data (existing medical records available as of the date of IEC submission) without any additional prospective components for research purposes. Hence, the process did not necessitate the obligation to obtain informed consent since the study did not involve identifiable individuals. Accordingly, the IEC gave permission for the informed consent form waiver before initiating the data collection process for this study.

The newly diagnosed adult ACS patients ( $>18$ years of age) who reported a medical emergency (cardiac unit) suffering from chest pain and suspected to represent UA or NSTEMI or STEMI confirmed by ECG report and biochemical assay and who required antithrombotic therapy (fondaparinux) were included in the study.

Patients were excluded from the study if they had a left bundle branch block at presentation; development of new Q-wave, permanent pacemakers, acute pericarditis; were on treatment with either heparin or oral anticoagulant; a history of any recent clinical infection and evidence of hospital-acquired infection, malignancy; active peptic ulcer disease or gastrointestinal bleeding; severe renal failure (GFR $15-29 \mathrm{ml} / \mathrm{min}$ ); or and severe hepatic disease.

\section{Study Design and Drug Allocation}

Medical records of the patient visits from the baseline to a period of 180 days ( 6 months) were taken into consideration. The patients were allocated to fondaparinux prefilled dose of $2.5 \mathrm{mg}$, once daily, subcutaneously (STEMI patients first dose was intravenous, then remaining doses were given subcutaneously).

The effectiveness outcome was assessed by the recurrence of symptomatic ACS event and 
Table 1 Baseline demographic characteristics $(n=611)$

\begin{tabular}{|c|c|}
\hline Parameter name & Parameter \\
\hline \multicolumn{2}{|l|}{ Demographics } \\
\hline $\begin{array}{l}\text { Age (in years), mean } \pm S D \text {, } \\
\text { (range) }\end{array}$ & $\begin{array}{l}58.69 \pm 9.01 \\
(29-85)\end{array}$ \\
\hline \multicolumn{2}{|l|}{ Gender $(n, \%)$} \\
\hline 1. Male & $549(89.85)$ \\
\hline 2. Female & $62(10.15)$ \\
\hline Weight $(\mathrm{kg})$, mean $\pm \mathrm{SD}$ & $65.73 \pm 7.73$ \\
\hline Height $(\mathrm{cm})$, mean $\pm S D$ & $167.83 \pm 6.61$ \\
\hline Pulse (bpm), mean \pm SD & $80.81 \pm 10.28$ \\
\hline $\mathrm{SBP}(\mathrm{mmHg})$, mean $\pm \mathrm{SD}$ & $128.76 \pm 15.07$ \\
\hline $\mathrm{DBP}(\mathrm{mmHg})$, mean $\pm \mathrm{SD}$ & $79.93 \pm 7.84$ \\
\hline \multicolumn{2}{|l|}{ Comorbidities $(n, \%)$} \\
\hline Hypertension & $150(24.54)$ \\
\hline Diabetes mellitus & $115(18.82)$ \\
\hline Dyslipidemia & $84(13.75)$ \\
\hline $\begin{array}{l}\text { Heart disease (CAD, heart } \\
\text { failure) }\end{array}$ & $6(0.98)$ \\
\hline Obesity & $5(0.82)$ \\
\hline \multicolumn{2}{|l|}{ Lifestyle related $(n, \%)$} \\
\hline Smokers & $48(7.86)$ \\
\hline Alcoholics & $18(2.95)$ \\
\hline \multicolumn{2}{|l|}{ History $(n, \%)$} \\
\hline \multicolumn{2}{|c|}{ 1. Previous medical history of CVD } \\
\hline Yes & $6(0.98)$ \\
\hline No & $605(99.02)$ \\
\hline \multicolumn{2}{|l|}{ 2. Family history of CVD } \\
\hline Yes & $25(4.09)$ \\
\hline No & $586(95.90)$ \\
\hline \multicolumn{2}{|c|}{ 3. Family history of hypertension } \\
\hline Yes & $40(6.54)$ \\
\hline No & $571(93.45)$ \\
\hline \multicolumn{2}{|l|}{ 4. Family history of diabetes } \\
\hline Yes & $31(5.07)$ \\
\hline
\end{tabular}

Table 1 continued

\begin{tabular}{ll}
\hline Parameter name & Parameter \\
\hline No & $580(94.92)$ \\
5. Family history of dyslipidemia & \\
Yes & $29(4.74)$ \\
No & $582(95.25)$ \\
6. Other family history & \\
Yes & $0(0)$ \\
No & $611(100)$ \\
\hline
\end{tabular}

type of recurrence (STEMI, NSTEMI, UA) at initial hospitalization, at 30 and 180 days. The symptomatic ACS was confirmed by ECG or biochemical assay and defined as repeat occurrences of MI or angina. Recurrence of MI and angina was defined as per the discretion of the physician in medical records.

The tolerability outcomes were evaluated by major bleeding and minor bleeding at initial hospitalization, at 30 days, and at 180 days. The definitions of effectiveness and tolerability outcomes, which were calculated by recurrence of symptomatic acute coronary syndrome, major bleeding, and minor bleeding, are provided in the supporting information. Outcomes were also assessed by baseline demographic details, biochemical parameters, angiography details, the hospitalization details of investigator drug, and other medications used along with investigator drug at baseline.

The details of revascularization (Table S9), anticoagulants during hospitalization (Table S6), and follow-up (Table S7) of 180 days are provided in the supporting information.

\section{Statistical Analysis}

All outcomes were presented using descriptive statistics. Continuous data are expressed as mean and SD and categorical data as numbers and percentages. The comparison of mean differences of data was analyzed by $t$ test and categorical variables by Chi-square test. A 
$p$ value $<0.05$ was considered statistically significant.

\section{RESULTS}

\section{Baseline Demographic Characteristics}

The mean age of the study population (Table 1) was $58.7 \pm 9.01$ years in a range of 29 to 85 years. The male proportion was about $90 \%$ and female $10 \%$. Comorbidities included hypertension $(24.54 \%)$, diabetes mellitus (18.82\%), dyslipidemia (13.75\%), heart disease $(0.98 \%)$, and obesity $(0.82 \%)$. Smoking was reported in $7.86 \%$ of patients. The majority of the population had STEMI with $46 \%$, UA was reported in $28 \%$ and NSTEMI in $25 \%$ of patients (Fig. 1). Detailed baseline characteristics, clinical features, and comorbidities are shown in Table 1.

\section{Biochemical Parameters}

At baseline, biochemical parameters revealed that $57.44 \%$ of patients with positive troponin I and $53.68 \%$ of patients with positive troponin $\mathrm{T}$, followed by $40.67 \%$ patients with CKMB. Among other laboratory values at the baseline visit, hematocrit (42.50\%), APTT (35.21 s), PT

\section{TYPE OF ACS (\%) - N=611}

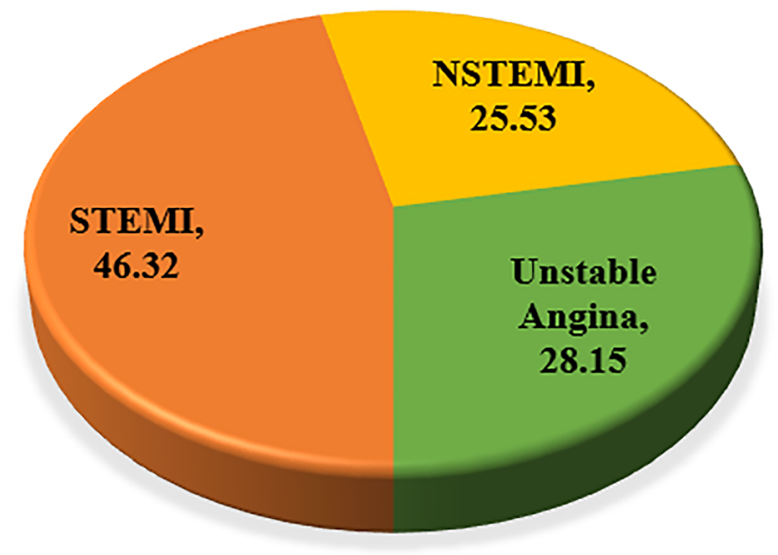

Fig. 1 Percentage of patients are given for each type of ACS category
$(14.62 \mathrm{~s})$, hemoglobin $(14.18 \mathrm{~g} / \mathrm{dl})$. Post-treatment, the liver and renal profile values at follow-up visits appeared normal, serum creatinine $(0.93 \mathrm{mg} / \mathrm{dl})$, BUN $(18.04 \mathrm{mg} / \mathrm{dl})$, and total bilirubin $(0.81 \mathrm{mg} / \mathrm{dl})$ (Table 2$)$.

\section{Hospitalization Details}

The average mean duration days of hospitalization for ACS treatment was 7.58 days (Supporting Table S5). The mean dose of fondaparinux prescribed was $2.5 \mathrm{mg} /$ daily for 6.72 mean duration of days subcutaneously.

\section{Other Medications Details}

Aspirin was used in nearly $82.16 \%(n=502)$ of the patients as concomitant treatment, followed by clopidogrel $71.85 \%(n=439)$, ticagrelor $8.67 \% \quad(n=53)$, and prasugrel $0.98 \%$ $(n=6)$ during hospitalization (Supporting Table S6).

\section{Angiography Details}

The baseline angiography report had shown $37.81 \%(n=231)$ of patients with one vessel disease, $38.78 \%(n=237)$ had two-vessel, and $23.40 \% \quad(n=143)$ had three-vessel disease (Fig. 2). Out of which, $75 \%$ of the patients had $90-100 \%$ of stenosis severity, $61 \%$ of patients had $70-80 \%$ severity and $33 \%$ of patients had $50-60 \%$ severity (Fig. 2B), while post-treatment, in between 1-6 months, angiography was performed on four patients $(0.65 \%)$, among which $0.32 \%(n=2)$ each had one- and two-vessel disease with $70-100 \%$ vessel blockage.

\section{Effectiveness Outcomes}

The recurrence of thrombosis events, duration of an event from the baseline, and types of recurrence are given in Fig. 3.

At baseline visit (during hospitalization) and at day 30, there were no recurrences $(n=0)$, while at day 180 , only $0.65 \%(n=4)$ events of recurrences had occurred, among which $0.16 \%$ $(n=1)$ recurrence events were NSTEMI and $0.49 \%(n=3)$ were UA type. The mean average 
Table 2 Biochemical parameters $(N=611)$

\begin{tabular}{|c|c|c|c|c|}
\hline Biochemical markers & Baseline & $\begin{array}{l}\text { Follow-up } 1 \\
\text { (1-2 months) }\end{array}$ & $\begin{array}{l}\text { Follow-up } 2 \\
\text { (3-4 months) }\end{array}$ & $\begin{array}{l}\text { Follow-up } 3 \\
\text { (5-6 months) }\end{array}$ \\
\hline \multicolumn{5}{|l|}{ Cardiac markers } \\
\hline \multicolumn{5}{|c|}{ 1. Troponin I (ng/ml), $n(\%)$} \\
\hline a. Negative $(<0.04)$ & $45(7.36)$ & $609(99.67)$ & $610(99.83)$ & $610(99.83)$ \\
\hline b. Positive (>0.04) & $351(57.44)$ & $2(0.33)$ & $1(0.16)$ & $1(0.16)$ \\
\hline c. No data & $215(35.18)$ & - & - & - \\
\hline \multicolumn{5}{|c|}{ 2. Troponin $\mathrm{T}(\mathrm{ng} / \mathrm{ml}), n(\%)$} \\
\hline a. Negative $(<0.04)$ & $87(16.24)$ & $609(99.67)$ & $610(99.83)$ & $610(99.83)$ \\
\hline b. Positive $(>0.04)$ & $328(53.68)$ & $2(0.33)$ & $1(0.16)$ & $1(0.16)$ \\
\hline c. No data & $197(32.24)$ & - & - & - \\
\hline 3. $\mathrm{LDH}(\mathrm{U} / \mathrm{l})$ & $300.88 \pm 98.51$ & $236.48 \pm 97.02$ & $227 \pm 42.76$ & $226.13 \pm 46.32$ \\
\hline \multicolumn{5}{|l|}{ mean $( \pm \mathrm{SD})$} \\
\hline 4. $\mathrm{CKMB}(\mathrm{IU} / \mathrm{l})$ & $40.67 \pm 15.87$ & $25.82 \pm 7.21$ & $24.18 \pm 6.90$ & $22.34 \pm 6.67$ \\
\hline \multicolumn{5}{|l|}{ mean $( \pm S D)$} \\
\hline \multicolumn{5}{|c|}{ Hematological parameters, mean $( \pm S D)$} \\
\hline Hemoglobin $(\mathrm{g} / \mathrm{dl})$ & $14.18 \pm 1.14$ & $14.29 \pm 1.05$ & $14.31 \pm 0.99$ & $14.28 \pm 1.02$ \\
\hline RBC count (cells/mcL) & $4.68 \pm 0.49$ & $4.69 \pm 0.46$ & $4.74 \pm 0.46$ & $4.73 \pm 0.49$ \\
\hline Hematocrit (\%) & $42.50 \pm 3.96$ & $42.91 \pm 3.62$ & $42.94 \pm 3.72$ & $42.85 \pm 3.81$ \\
\hline \multirow[t]{2}{*}{ Platelet count $(\mathrm{mcL})$} & $215,180.95$ & $214,673.28$ & $214,404.91$ & $215,204.58$ \\
\hline & $\pm 48,521.79$ & $\pm 46,741.22$ & $\pm 47,373.92$ & $\pm 48,168.03$ \\
\hline $\mathrm{PT}(\mathrm{sec})$ & $14.62 \pm 1.05$ & $14.11 \pm 0.92$ & $14.11 \pm 0.93$ & $13.89 \pm 0.74$ \\
\hline INR & $1.16 \pm 0.08$ & $1.14 \pm 0.07$ & $1.13 \pm 0.09$ & $1.14 \pm 0.08$ \\
\hline $\mathrm{PT} / \mathrm{INR}$ & $3.47 \pm 4.58$ & $3.15 \pm 4.04$ & $3.17 \pm 4.11$ & $3.14 \pm 4.05$ \\
\hline APTT (sec) & $35.21 \pm 4.72$ & $35.92 \pm 3.93$ & $36.25 \pm 3.78$ & $35.80 \pm 3.88$ \\
\hline \multicolumn{5}{|l|}{ Liver enzyme, mean $( \pm S D)$} \\
\hline AST (IU/l) & $27.84 \pm 7.65$ & $26.63 \pm 7.51$ & $26.85 \pm 7.75$ & $26.85 \pm 7.72$ \\
\hline $\operatorname{ALT}(\mathrm{IU} / \mathrm{l})$ & $27.94 \pm 7.42$ & $27.27 \pm 7.20$ & $27.82 \pm 7.46$ & $27.59 \pm 7.23$ \\
\hline $\operatorname{ALP}(\mathrm{IU} / \mathrm{l})$ & $82.32 \pm 14.91$ & $80.97 \pm 14.52$ & $81.92 \pm 13.47$ & $81.89 \pm 13.57$ \\
\hline Total bilirubin (mg/dl) & $0.81 \pm 0.31$ & $0.79 \pm 0.30$ & $0.81 \pm 0.312$ & $0.81 \pm 0.32$ \\
\hline \multicolumn{5}{|l|}{ Lipid profile, mean $( \pm S D)$} \\
\hline Total cholesterol (mg/dl) & $187.82 \pm 21.82$ & $177.37 \pm 29.21$ & $175.94 \pm 31.04$ & $175.15 \pm 32.77$ \\
\hline Triglycerides (mg/dl) & $173.84 \pm 35.51$ & $165.98 \pm 42.59$ & $162.51 \pm 47.35$ & $164.97 \pm 43.89$ \\
\hline HDL (mg/dl) & $42.42 \pm 6.60$ & $43.21 \pm 5.89$ & $43.33 \pm 5.60$ & $43.84 \pm 5.45$ \\
\hline
\end{tabular}


Table 2 continued

\begin{tabular}{|c|c|c|c|c|}
\hline Biochemical markers & Baseline & $\begin{array}{l}\text { Follow-up } \\
1(1-2 \text { months })\end{array}$ & $\begin{array}{l}\text { Follow-up } \\
2(3-4 \text { months })\end{array}$ & $\begin{array}{l}\text { Follow-up } \\
3(5-6 \text { months })\end{array}$ \\
\hline $\operatorname{LDL}(\mathrm{mg} / \mathrm{dl})$ & $102.94 \pm 31.28$ & $98.11 \pm 28.26$ & $97.66 \pm 26.66$ & $96.06 \pm 25.91$ \\
\hline \multicolumn{5}{|l|}{ Renal profile, mean $( \pm S D)$} \\
\hline Serum creatinine $(\mathrm{mg} / \mathrm{dl})$ & $0.93 \pm 0.18$ & $0.93 \pm 0.18$ & $0.93 \pm 0.18$ & $0.94 \pm 0.18$ \\
\hline Serum sodium $(\mathrm{mEq} / \mathrm{l})$ & $140.20 \pm 3.61$ & $140.25 \pm 3.58$ & $140.22 \pm 3.61$ & $140.22 \pm 3.59$ \\
\hline Serum potassium $(\mathrm{mEq} / \mathrm{l})$ & $4.34 \pm 0.60$ & $4.36 \pm 0.59$ & $4.35 \pm 0.60$ & $4.36 \pm 0.60$ \\
\hline BUN (mg/dl) & $18.04 \pm 5.94$ & $18.12 \pm 6.12$ & $17.62 \pm 5.15$ & $17.62 \pm 5.11$ \\
\hline
\end{tabular}

duration of days for the recurrence occurred from the baseline visit was 172.75 days.

\section{Tolerability Outcome}

Bleeding Complications Major bleeding events did not occur during the entire study period, while minor bleeding events occurred in $0.98 \%(n=6)$ patients during baseline (during hospitalization) and $0.16 \%(n=1)$ patients within 30 days (Fig. 4). None of the bleeding events were statistically significant $(p$ value $>0.05)$.

Stent Thrombosis No incidences of stent thrombosis were reported during the entire study period.

\section{DISCUSSION}

Fondaparinux is a low molecular weight heparin anticoagulant and is one of the first synthetic molecules developed for targeted action against specific coagulation proteins [3-18].

Extensive preclinical and clinical studies have been carried out with fondaparinux with large-scale randomized controlled trials in clinical settings to determine the efficacy and safety in ACS. The present retrospective, observational study provided real-world evidence of the effectiveness and tolerability of fondaparinux in ACS patients. Being a retrospective analysis, this study analyzed use and outcomes of fondaparinux and had no influence on physicians where they are using the drug.
The results indicated that fondaparinux was an effective drug of choice in managing the symptomatic ACS in real-world practice. Due to its selective indirect inhibition of factor $\mathrm{Xa}$, it allows greater predictability of the anticoagulant effect and allows a fixed dose to be given with no requirement to undertake routine monitoring of anticoagulant effect. It is $100 \%$ bio-available after subcutaneous injection, and it has a much longer half-life than UFH and LMWHs of about $18 \mathrm{~h}$, allowing it to be given once daily.

The recurrence rate of myocardial infarction/ angina events was recorded at a rate of $0.65 \%$ of the patients at 180 days, among which $0.49 \%$ of the patients had UA, and $0.16 \%$ of patients had NSTEMI type of recurrence. During the baseline (hospitalization), when initial treatment was prescribed/given to the patients with ACS and the first 30 days of follow-up, no recurrences were observed. The incidences of minor bleeding were recorded in $0.98 \%$ of patients at baseline and $0.16 \%$ at 30 days, while no major bleeding was observed throughout the study period. The current study results on clinical recovery revealed that $99.18 \%$ of the patients without any complications during the study period of 6 months. No cases of stent thrombosis were reported.

These observations agreed with the findings of studies where fondaparinux was found to be more effective and safer in patients with ACS. Similar results were observed in the research by Alexandre et al. wherein fondaparinux showed a significant reduction in mortality without 
a

\section{Number of Coronary Vessel Involvement $(\mathbf{N}=611)$}

Angiography report - Baseline $\square$ Angiography report - 180 days

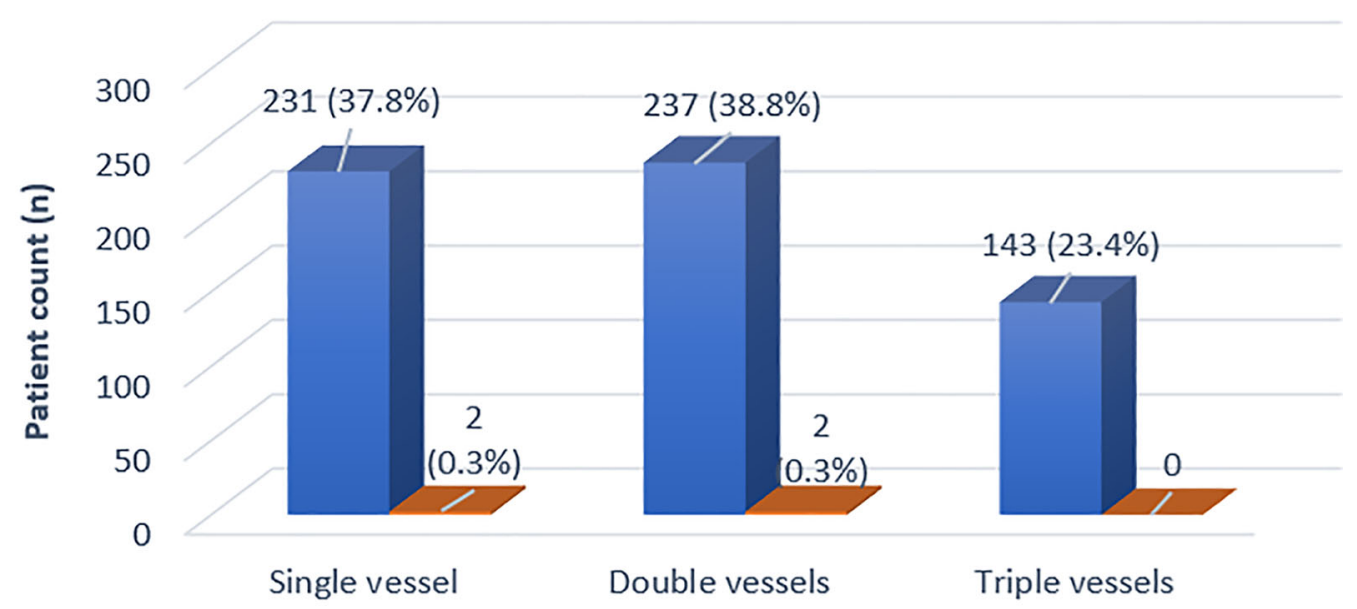

Number of Coronary Vessel Involvement

b

Severity of Stenosis $(\mathrm{N}=611)$

$\square$ Angiography report - Baseline $\square$ Angiography report - 180 days

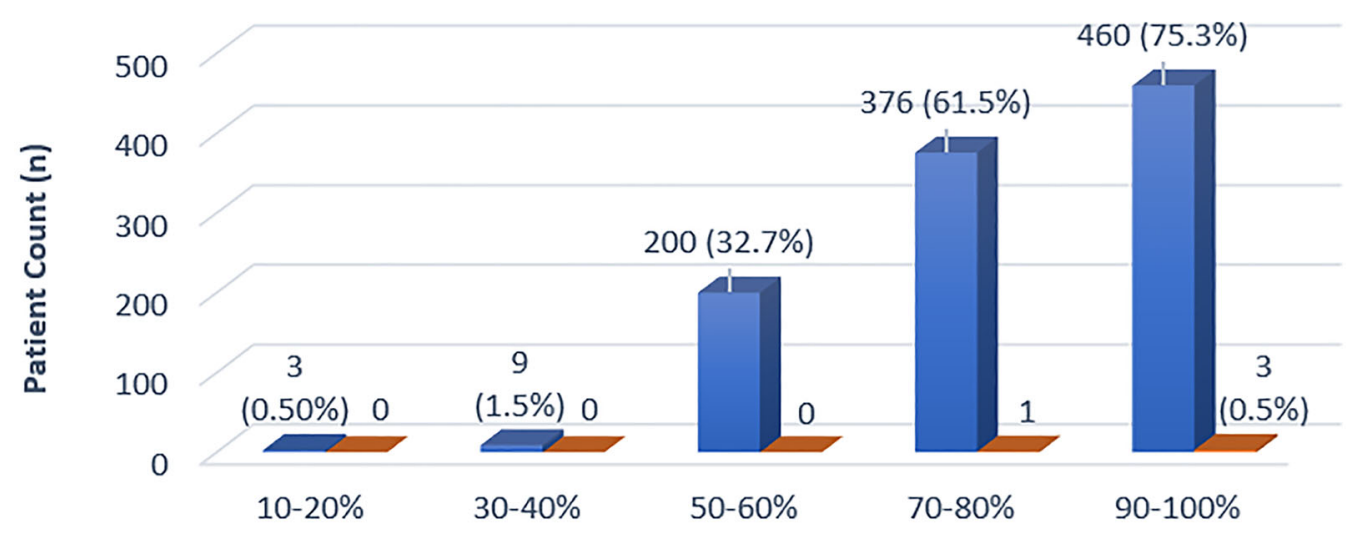

Severity of Stenosis

Fig. 2 a Number of coronary vessel involvement. b Severity of stenosis at baseline and post treatment (180 days) based on anigography reports

increasing severe bleeding in patients with STEMI-ACS [11]. A real-world study by Soeiro et al. in the Brazilian population has also shown a significant reduction of combined events and bleeding with fondaparinux [19]. A study by Shah et al. further supported better efficacy and 
a

Count of Recurrent Events ( $N=611)$

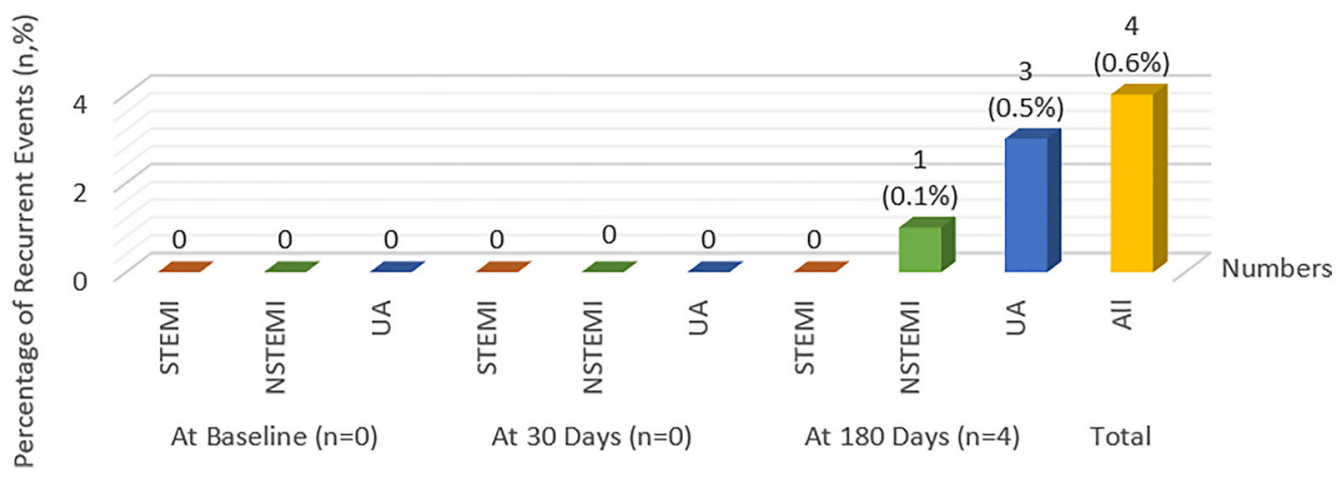

b Duration of Recurrent Event from Baseline (N=611)

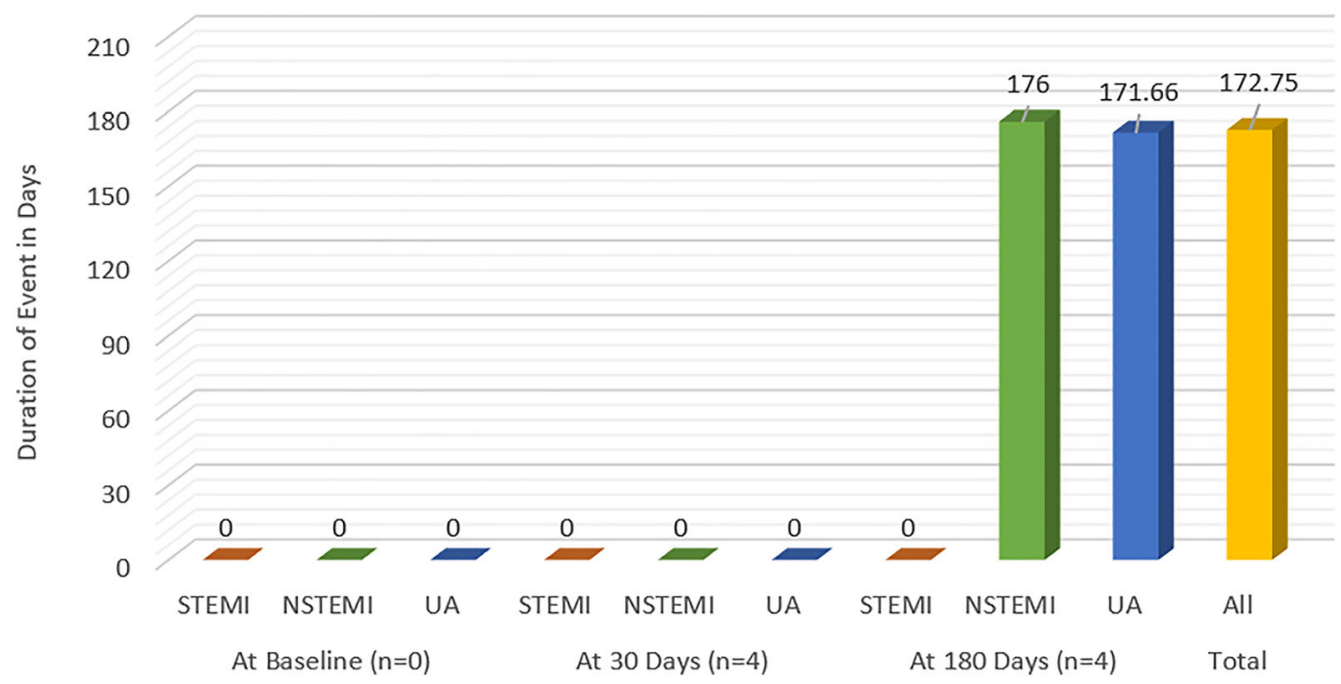

Fig. 3 a Count of recurrent events across three type of ACS categories during the study period is given in the above panel. b Duration of recurrent events is given in the below panel

safety of fondaparinux among the patients diagnosed with ACS. They found that fondaparinux appeared to be better in efficacy, as indicated by a numerically more decrease in recurrence of angina or MI, and also had a better safety profile, as there were no incidences of bleeding and concluded that fondaparinux was an attractive option in ACS patients [2]. A metaanalysis by Brito et al. suggested that fondaparinux was the only factor $\mathrm{Xa}$ inhibitor that lowers the risk of all-cause mortality and the risk of major or minor bleeding [20]. Additionally, a study by Wienbergen et al. presented fondaparinux as a safe and effective new antithrombotic agent in the treatment of ACS [21].

A significant advantage of fondaparinux is its ease of use. A single daily subcutaneous administration of $2.5 \mathrm{mg}$ fondaparinux provides stable and predictable anti-coagulation without the need for laboratory control of coagulation parameters. Therefore, it can be used in a wide range of patients and settings.

Prior studies set up the feasibility of the use of fondaparinux in ACS patients, but the significant evidence for its efficacy and safety in 


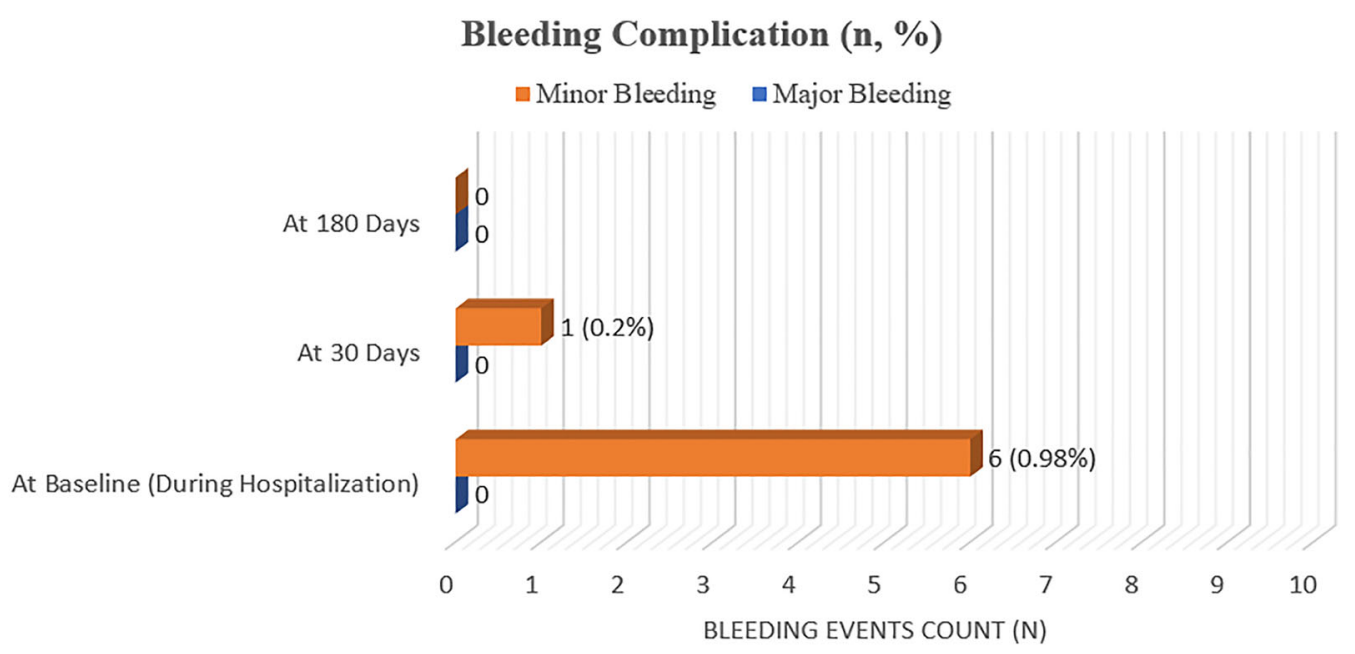

Fig. 4 Major and minor bleeding events at baseline, 30 days, and 180 days

ACS were investigated in two pivotal randomized, double-blinded, non-inferiority, controlled trials, the OASIS-5 and OASIS- 6 trials. The results in the present analysis had shown that the risk of recurrence and bleeding events did not increase with the use of the study drug fondaparinux at all time points (at 9, 30, and 180 days), and these results were consistent with the findings of two pivotal OASIS-5 and OASIS-6 trials which showed markedly lower rates of recurrent MI and major bleeding with fondaparinux. The OASIS-5 study was conducted on 20,078 [21] in-patients with the primary objective of evaluating the efficacy and safety of fondaparinux in non-ST-elevation ACS (NSTE-ACS). The study proved its objective of showing non-inferiority of fondaparinux over LMWH by demonstrating primary outcomes at day 9, which was sustained at 30, 90, and 180 days. In this study, fondaparinux reduced major bleeding incidences by half and minor bleeding by approximately $66 \%$. Thus, there was a $20 \%$ improvement in the net clinical benefit compared to LMWH [23]. The OASIS-6 study was performed on 12,092 patients with ST-elevation myocardial infarction ACS (STEMIACS) [21] aimed to demonstrate the superiority of fondaparinux in terms of anticoagulant efficacy with reducing the rate of bleeding risk. The results showed significantly fewer incidences of death and recurrent MI by 21\% and severe bleeding by $34 \%$ [22]. Similarly, the current study had proven its objective of showing the effectiveness and tolerability of fondaparinux by reducing the risk of recurrent events and major bleeding, which resulted in a positive clinical benefit in the improvement of ACS symptoms.

\section{LIMITATIONS}

This real-world evidence study has some limitations, as it is a retrospective observational study and data were not randomized. Also, the patients themselves were responsible for adhering to and complying with the given follow-up antiplatelet medications. Instead of a single protocol, different methods were used to detect the ACS recurrence at various centers. Classification of bleeding events was vast and different methods were used to classify the bleeding at multiple centers. This may have caused a variation in the measurements. Other limitations include the missing data of various investigation parameters. However, it is not likely that these limitations have had an impact on the study outcome. Also, the observations need to be ascertained further by means of additional long-term studies. 


\section{CONCLUSIONS}

The current RWE study was specifically designed to determine the effectiveness and tolerability of fondaparinux prophylaxis in symptomatic ACS, involving 611 patients. No recurrent incidences of ACS were observed during hospitalization, and within 30 days, only $0.65 \%$ incidences of ACS recurrence were reported within 180 days. Also, no incidence of major bleeding with fondaparinux was observed throughout the study period. Only $0.98 \%$ incidences of minor bleeding were observed during the hospitalization and $0.16 \%$ incidences within 30 days, and none of them were statistically significant. There were no cases of stent thrombosis reported during the study.

In conclusion, this study provided evidence of the effectiveness and tolerability of fondaparinux and demonstrated it as a preferable choice in terms of management and prevention of ischemic events and major bleeding after initiation of the treatment in ACS patients in a real-world setting. This new standard once-daily pre-filled subcutaneous anticoagulant shows a favorable benefit-risk ratio in real-world practice and improved patients' overall prognosis with ACS. Also, the once-daily pre-filled injection showed no incidences of catheter-related thrombosis during the invasive procedures.

The study concludes that the positive effects of fondaparinux are due to its ability to initiate selective inhibition of factor $\mathrm{Xa}$, and it is easy to use (2.5 mg pre-filled injection once daily for all ACS patients), as no dose adjustments are necessary, which limit dosing errors, its predictable linear pharmacokinetics, Also, this new-age anticoagulant provides various advantages including ease of use, which provides a stable and predictable anti-coagulation without the need of laboratory parameters monitoring and minimal risk of drug interactions. Moreover, regardless of patient weight, it is prescribed as a single dose and provides a lower treatment cost. Because of this feature, it should be considered as a cost-effective option for the treatment of patients with ACS.

The current EMR-based retrospective realworld evidence study has provided the extended and the needed additional information about the effectiveness and tolerability of fondaparinux as a non-surgical therapy of choice for the management of symptomatic ACS in the Indian population.

\section{ACKNOWLEDGEMENTS}

Funding. The study and the journal's Rapid Service Fee were funded by Dr. Reddy's Laboratories (DRL).

Disclosures. The authors, Dr. Jamshed Dalal, Dr. Jagdish Chander Mohan, Dr. Sunil Sathe, Dr. Arramraju Sreenivas Kumar, and Dr. Jagdish Hiremath are the advisory board members for Dr. Reddy's Laboratories Ltd. Dr. Mohammed Yunus Khan, Dr. Kumar Gaurav, Dr. Amey Mane, and Sucheta Pandit declare that they work in Medical Affairs Department in Dr. Reddy's Laboratories Ltd, Hyderabad, India. Dr. Bhavesh Meel and Dr. Anand Subramaniyan have nothing to disclose.

Data Availability. All the data outcomes generated during and/or analyzed during the current study are included in this published article.

Compliance with Ethics Guidelines. An independent ethics committee (IEC), Royal Pune Independent Ethics Committee, located in Pune, India, approved the study protocol and also gave permission to analyze the available retrospective data. This being a retrospective study and used the anonymized or anonymous data (existing medical records available as of the date of IEC submission) without any additional prospective components for research purposes. Hence, the process did not necessitate the obligation to obtain informed consent since the study did not involve identifiable individuals. Accordingly, IEC gave permission for the informed consent form waiver before initiating the data collection process for this study.

Author Contributions. All the authors of this paper contributed to the work and 
preparation of the manuscript. Authors from Dr. Reddy's Laboratories had contributed towards the conceptualizing the study hypothesis, design of the study, data analysis and interpretation of study outcomes, and compiling the manuscript. The advisory board members significantly contributed to revise the manuscript critically for important intellectual content and final approval and review. Dr. B. Meel and Dr. A. Subramaniyan provided the required study data inputs and important insights on patient outcomes.

Medical Writing, Editorial and Other Assistance. The authors thank Mrs. Mohini Gahlot (Medical Writer), Dr. Srivani Palukuri (Clinical Research Scientist), and Dr. Saurav Deka (AVP, Clinical Operations) from Sekhmet Technologies Private Limited (THB), India, for their support to the preparation of the manuscript. Dr. Reddy's Laboratories has funded the medical writing assistance.

Authorship. All named authors meet the International Committee of Medical Journal Editors (ICMJE) criteria for authorship for this article, take responsibility for the integrity of the work as a whole, and have given their approval for this version to be published.

Open Access. This article is licensed under a Creative Commons Attribution-NonCommercial 4.0 International License, which permits any non-commercial use, sharing, adaptation, distribution and reproduction in any medium or format, as long as you give appropriate credit to the original author(s) and the source, provide a link to the Creative Commons licence, and indicate if changes were made. The images or other third party material in this article are included in the article's Creative Commons licence, unless indicated otherwise in a credit line to the material. If material is not included in the article's Creative Commons licence and your intended use is not permitted by statutory regulation or exceeds the permitted use, you will need to obtain permission directly from the copyright holder. To view a copy of this licence, visit http://creative commons.org/licenses/by-nc/4.0/.

\section{REFERENCES}

1. Sanchis-Gomar F. Epidemiology of coronary heart disease and acute coronary syndrome. Ann Transl Med. 2016;4(13):256. https://doi.org/10.21037/ atm.2016.06.33.

2. Shah S, et al. Comparative evaluation of efficacy, safety and haemostatic parameters of enoxaparin and fondaparinux in unstable coronary artery disease. J Clin Diagn Res. 2014;8(1):31-4. https://doi. org/10.7860/JCDR/2014/6359.3908.

3. Chaturvedi V, Karthikeyan G. Fondaparinux in acute coronary syndromes. Expert Opin Drug Metab Toxicol. 2009;5(12):1615-23. https://doi. org/10.1517/17425250903456039.

4. Overbaugh KJ. Acute coronary syndrome. Am J Nurs. 2009;109(5):42-53. https://doi.org/10.1097/ 01.NAJ.0000351508.39509.e2.

5. Amsterdam EA, et al.AHA/ACC guideline for the management of patients with non-ST-elevation acute coronary syndromes: a report of the American College of Cardiology American Heart Association task force on practice guidelines. Circulation. 2014;23(25):344-426. https://doi.org/10.1161/CIR. 0000000000000134 .

6. Bassand JP, et al. Efficacy and safety of fondaparinux in patients with acute coronary syndromes. Expert Rev Cardiovasc Ther. 2007;5(6):1013-26. https://doi.org/10.1586/14779072.5.6.1013.

7. Grech Ever D, Ramsdale DR. Acute coronary syndrome: unstable angina and non-ST segment elevation myocardial infarction. BMJ. 2003;326:1259. https://doi.org/10.1136/bmj.326.7401.1259.

8. Grech ED, Ramsdale DR. Acute coronary syndrome: unstable angina and non-ST segment elevation myocardial infarction. BMJ. 2003;326:1259. https:// doi.org/10.1136/bmj.326.7401.1259.

9. Makki N, et al. Acute coronary syndrome. J Intensive Care Med. 2015;30(4):186-200. https://doi.org/ $10.1177 / 0885066613503294$.

10. Adam AM, et al. Prognostic value of blood count parameters in patients with acute coronary syndrome. Indian Heart J. 2018;70(2):233-40. https:// doi.org/10.1016/j.ihj.2017.06.017.

11. Turpie AG. Fondaparinux in the management of patients with ST-elevation acute myocardial infarction. Vasc Health Risk Manag. 2006;2(4): 371-8. https://doi.org/10.2147/vhrm.2006.2.4.371.

12. Eikelboom JW, et al. Unfractionated heparin and low-molecular-weight heparin in ACS without ST 
elevation: a meta-analysis [published correction appears in Lancet 2000 Aug 12;356(9229):600]. Lancet. 2000;355(9219):1936-42. https://doi.org/ 10.1016/S0140-6736(00)02324-2.

13. Antman EM, et al. Enoxaparin versus unfractionated heparin with fibrinolysis for ST-elevation myocardial infarction. N Engl J Med. 2006;354(14): 1477-88. https://doi.org/10.1056/NEJMoa060898.

14. Karthikeyan G, et al. Fondaparinux in the treatment of acute coronary syndromes: evidence from OASIS 5 and 6. Expert Rev Cardiovasc Ther. 2009;7(3):241-9. 14779072.7.3.241.

https://doi.org/10.1586/

15. Moon JY, et al. The role of oral anticoagulant therapy in patients with acute coronary syndrome. Ther Adv Hematol. 2017;8(12):353-66. https://doi. org/10.1177/2040620717733691.

16. Onwordi EN, et al. Anticoagulant therapy for acute coronary syndromes. Interv Cardiol. 2018;13(2): 87-92. https://doi.org/10.15420/icr.2017:26:1.

17. Caterina DR, Goto S. Targeting thrombin long-term after an acute coronary syndrome: opportunities and challenges. Vascul Pharmacol. 2016;81(6): 1-14. https://doi.org/10.1016/j.vph.2016.03.003.
18. Hamedi N, Wright P. Fondaparinux and acute coronary syndrome. Br J. 2013;7(11):15-26. https:// doi.org/10.12968/bjca.2012.7.11.545.

19. Soeiro ADM, et al. Fondaparinux versus enoxaparin-which is the best anticoagulant for acute coronary syndrome? Brazilian Registry Data. Arq Bras Cardiol. 2016;107(3):239-44. https://doi.org/ 10.5935/abc. 20160127.

20. Brito V, et al. Factor Xa inhibitors for acute coronary syndromes. Cochrane Database Syst Rev. 2011;1:7038. https://doi.org/10.1002/14651858. CD007038.pub2.

21. Wienbergen H, Zeymer U. Management of acute coronary syndromes with fondaparinux. Vasc Health Risk Manag. 2007;3(3):321-9.

22. Trailokya A, et al. Fondaparinux in acute coronary syndromes. J Assoc Physicians India. 2015;63(7): 83-7.

23. Larmore $\mathrm{C}$, et al. Real-world comparison of prasugrel with ticagrelor in patients with ACS treated with percutaneous coronary intervention in the United States. Catheter Cardiovasc Interv. 2016;88(4):535-44. https://doi.org/10.1002/ccd. 26279 . 